\title{
The Optimization of Fracture System Conductivity in Tight Oil Reservoirs
}

\author{
G.F. Liu \\ CMOE Key Laboratory of Petroleum Engineering \\ China University of Petroleum \\ 18 Fuxue Road, Changping, Beijing, 102249, China
}

\author{
T.P. Wu \\ CMOE Key Laboratory of Petroleum Engineering \\ China University of Petroleum \\ 8 Fuxue Road, Changping, Beijing, 102249, China
}

\author{
J.J. Zhang \\ ConocoPhillips Company \\ Houston, Texas, 77843, USA
}

\author{
Z. Meng \\ CMOE Key Laboratory of Petroleum Engineering \\ China University of Petroleum \\ 18 Fuxue Road, Changping, Beijing, 102249, China
}

\author{
J.T. Wang \\ Oil and Gas Technology Institute \\ Changqing Oil Field Company \\ Xi'an, 710000, China \\ Y.J. Zhang \\ Oil and Gas Technology Institute \\ Changqing Oil Field Company \\ Xi'an, 710000, China
}

\begin{abstract}
The network fracturing has become the key technology to develop the tight oil reservoirs. This fracturing technology creates a complex fracture network in the stimulated region. The primary goal of this paper is to optimize the fracture system conductivity in tight oil reservoirs, and to analyse the sensitivity of fracture system conductivity ratio on matrix permeability. To accurately capture the flow characteristic in the fracture system, a DK-LS-LGR numerical model was adopted. Then the influence of primary fracture conductivity and fracture network conductivity on oil recovery was analysed respectively, and a dimensionless conductivity ratio of primary fracture and fracture network was introduced to make the research results universal. This work also considered the influence of matrix permeability on conductivity ratio and obtained a uniform trend with the previous given condition.
\end{abstract}

Keywords-network fracturing; tight oil reservoir; primary fracture; fracture system conductivity ratio

\section{INTRODUCTION}

The exploitation of tight oil has become an ever increasing component of the word energy supply in the last few years [1]. This motivated the tremendous development of reservoir stimulation technologies, such as the network fracturing, also known as stimulated reservoir volume or SRV [2, 3].

The network fracturing technology activates the existing natural fractures and communicates them with the hydraulic fractures to form a complex fracture network by large-volume high-rate hydraulic fracturing treatments. This technology frees the whole stimulated region and forms a three-dimensional fracture network, which can be regarded as the biggest breakthrough or say it a significant revolution in the fracturing history $[4,5]$. Since network fracturing has been applied in the shale gas reservoirs for years, the connotation of this technology and its application conditions has been studied by many researchers, and all of that will not be repeated here. This paper will concentrate on the optimization of fracture system conductivity in tight oil reservoirs.

In 2009, Cipolla simulated the fracture performance in unconventional gas reservoirs by assuming the proppant location within the fracture network in two limiting cases and indicated that the fracture system with primary fractures performs better in the fractured wells. According to his research, there are two limiting cases, namely, the proppant is evenly distributed throughout the complex fracture system or the proppant is mainly concentrated in a dominant primary fracture that is connected to an unpropped or partially propped complex fracture network $[6,7,8,9]$.

As this paper adopt the conductivity ratio of primary fracture and fracture network, and the case that proppants distributed evenly can be included when setting the conductivity ratio to 1 . This paper combines the work of Cipolla in fracture performance evaluation in unconventional gas reservoirs, and the work of Barry Rubin in fracture network simulation [11]. By applying the proppant distribution hypothesis to horizontal well network fracturing, a typical simulation model is established. Then the correlation between the fracture system conductivity and oil recovery was studied and optimized the conductivity ratio of network fracturing for the given reservoir. Finally, the sensitivity of matrix permeability on optimized conductivity ratio was analysed and obtained the optimal fracture system conductivity ratio under different matrix permeability.

\section{MODELLING METHODOLOGY OF FRACTURE NETWORK}

There have been many literatures regarding the modelling of fracture network in hydraulically-stimulated tight reservoirs. 
Work by Mayerhoffer and Barry Rubin are two of the excellent examples.

Mayerhoffer [10] discussed using explicit fracture networks to model the flow within a fractured shale reservoir in numerical simulation, and emphasized the necessary to model fractures explicitly at their true width (on the order of $0.001 \mathrm{~m}$.). However, modelling fractures at their true width means that there will be tremendous number of grids. This requires significant execution times to run the models, making it limited in application.

Barry Rubin [11] compared the classical DK model, the MINC (multiple interacting continua) model and the DK-LSLGR model in simulating network fracturing in shale gas reservoirs. The results demonstrate that the DK-LS-LGR model can best characterize the complex fracture system. This model adopts a logarithmically spaced local grid refinement to characterize the hydraulic fractures and a dual permeability property to simulate the natural fractures.

According to the presentation above, this paper will adopt the DK-LS-LGR method to build a simulation model for the study area. The reservoir pressure is $14.7 \mathrm{MPa}$, the reservoir thickness is 20 meters, the matrix permeability is $0.23 \mathrm{mD}$, the porosity is $9.4 \%$. The horizontal well is 700 meters long and fractured 7 stages, with two clusters per stage, the typical model is shown as fig. 1.

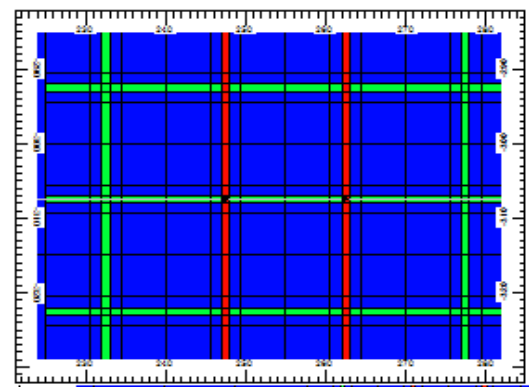

FIGURE I. DK-LS-LGR FRACTURE NETWORK SYSTEM, THE BLUE GRIDS REPRESENT THE MATRIX CELLS, THE GREEN DIVIDED GRIDS REPRESENT THE FRACTURE NETWORKS, AND THE RED DIVIDED GRIDS REPRESENT THE PRIMARY FRACTURES

\section{OPTIMIZATION OF FRACTURE SYSTEM CONDUCTIVITY}

\section{A. Optimization of Fracture Network Conductivity}

In this work, the fracture network refers to cross paired fractures except the primary fractures, and its productivity is far lower than the primary fracture conductivity. The fracture network conductivity is set as $1 \mathrm{mD} \cdot \mathrm{m}, 5 \mathrm{mD} \cdot \mathrm{m}, 10 \mathrm{mD} \cdot \mathrm{m}$, $20 \mathrm{mD} \cdot \mathrm{m}, 30 \mathrm{mD} \cdot \mathrm{m}$ and $40 \mathrm{mD} \cdot \mathrm{m}$ separately. And the primary fracture conductivity is $200 \mathrm{mD} \cdot \mathrm{m}$. The recovery curves under different fracture network conductivities are compared then, shown as fig. 2 .

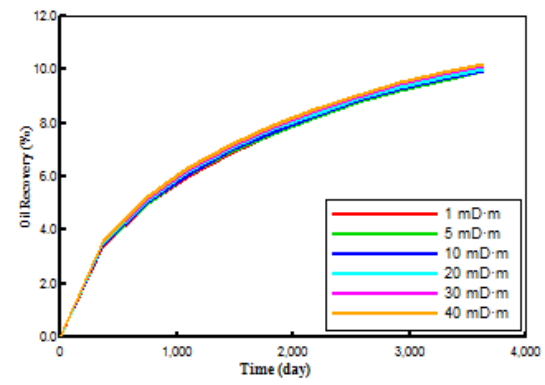

FIGURE II. CURVE OF OIL RECOVERY AND FRACTURE NETWORK CONDUCTIVITY

Fig 2 shows that the fracture network conductivity has little influence on the oil recovery, the curve of all the 6 scenarios is almost the same. This phenomenon indicates that if in the presence of primary fracture, the primary fracture is the dominant factor that affects the oil recovery while the fracture network has no significant effect. This indicates that the complex fracture system which contains some primary fractures is a better choice in network fracturing. In practice, there is some means by which the primary fractures can be formed, such as pumping larger proppant at the beginning and of the fracturing treatment, for that larger proppant may be less likely to enter the network fractures and more likely to accumulate in the primary fracture, thus increasing primary fracture conductivity and contributing to form a complex fracture system containing primary fractures and fracture networks.

\section{B. Optimization of Primary Fracture Conductivity}

According to results above, the primary fracture can significantly improve the oil recovery, but how much conductivity do we need to maximize its contribution? The larger, the better? This is absolutely not the right answer. As we know, doubling the fracture conductivity will definitely lead to increase of the cost far more than double and will undoubtedly increase the difficulty of fracturing treatment. So there will be a critical value of primary fracture conductivity under given conditions. This part will focus on the optimization of this value. Define the fracture network conductivity as $20 \mathrm{mD} \cdot \mathrm{m}$, and the primary fracture conductivity is set to $100 \mathrm{mD} \cdot \mathrm{m}$, $200 \mathrm{mD} \cdot \mathrm{m}, 300 \mathrm{mD} \cdot \mathrm{m}, 400 \mathrm{mD} \cdot \mathrm{m}$ and $500 \mathrm{mD} \cdot \mathrm{m}$. Then the recovery curves are compared in fig.3, and the correlation between primary fracture conductivity and 10 years oil recovery is shown in fig. 4 .

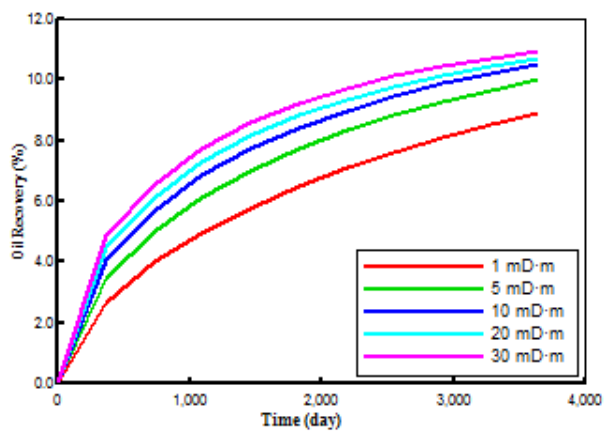

FIGURE III. CURVE OF WELL RECOVERY AND PRIMARY FRACTURE CONDUCTIVITY 


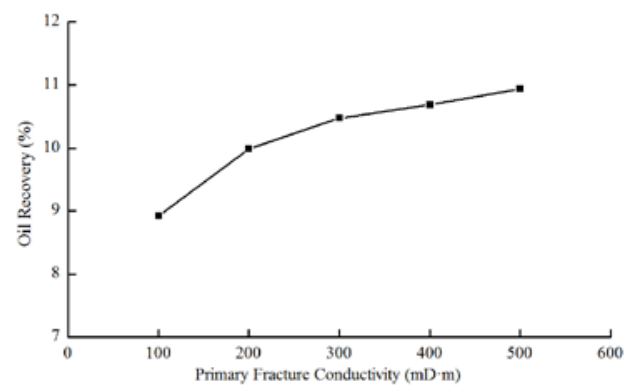

FIGURE IV. RELATIONSHIP BETWEEN PRIMARY FRACTURE CONDUCTIVITY AND RECOVERY

Fig.3 shows that the oil recovery increases as the primary fracture conductivity increases, but the increase becomes gentle as the value of primary fracture conductivity reaches a critical value. From fig.4 we know that this critical value is about $200 \mathrm{mD} \cdot \mathrm{m}$. This indicates that there is no need to pursue primary conductivity higher than $200 \mathrm{mD} \cdot \mathrm{m}$ in the stimulation design of this well.

\section{Optimization of Fracture System Conductivity Ratio}

To improve the versatility of the results, define $\lambda$ as the fracture system conductivity ratio of primary fracture and fracture network. For the case with no primary fractures, the $\lambda$ can be set as 1 . Define the fracture network conductivities as $5 \mathrm{mD} \cdot \mathrm{m}, 10 \mathrm{mD} \cdot \mathrm{m}, 20 \mathrm{mD} \cdot \mathrm{m}, 30 \mathrm{mD} \cdot \mathrm{m}$, and the $\lambda$ array is 1,2 , 5, 10 and 20. Then oil recovery profiles with different conductivity ratios are compared in given fracture network conductivities, the results is shown as fig.5.

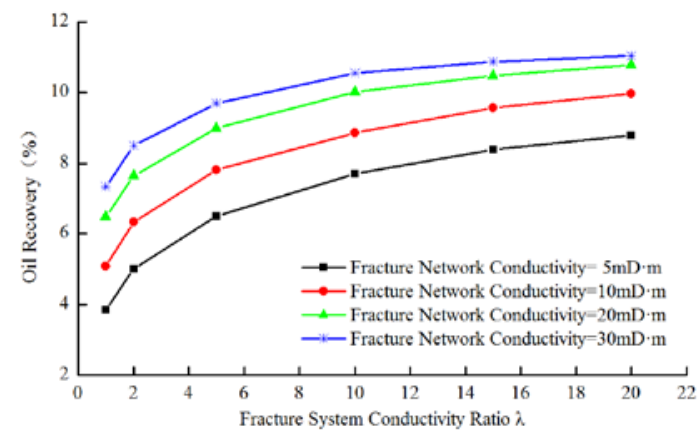

FIGURE V. THE RELATIONSHIP BETWEEN FRACTURE SYSTEM CONDUCTIVITY RATIOS AND OIL RECOVERY

From fig.5 we can see that the oil recovery shows a uniform increase tendency as the conductivity ratio $\lambda$ increase in spite of the difference of fracture network conductivities, but the trends get gentle as the $\lambda$ gets larger. Besides, when the $\lambda$ exceed 10 , the additional $\lambda$ provides little increase in oil recovery. And this critical value of $\lambda$ is uniform under different fracture network conductivities. This indicates that if the appropriate fracture network conductivity is determined, then we can easily get the reasonable primary fracture conductivity by simply multiplying the value by 10 . This will save lots of work in the fracturing design and optimization.

\section{INFLUENCE OF MATRIX PERMEABILITY ON OPTIMIZED FRACTURE SYSTEM CONDUCTIVITY RATIO}

As reservoir conditions may vary from each other quite a lot, whether the above results are suitable for other reservoirs require further study. This part will analyse the influence of matrix permeability on the optimized fracture system conductivity ratio. To simplify the job, the fracture network conductivity was assumed to be $20 \mathrm{mD} \cdot \mathrm{m}$ and remain the same in all the 36 scenarios. Then, the relationship between the fracture system conductivity ratios and oil recovery under different matrix permeability was plotted as fig.6.

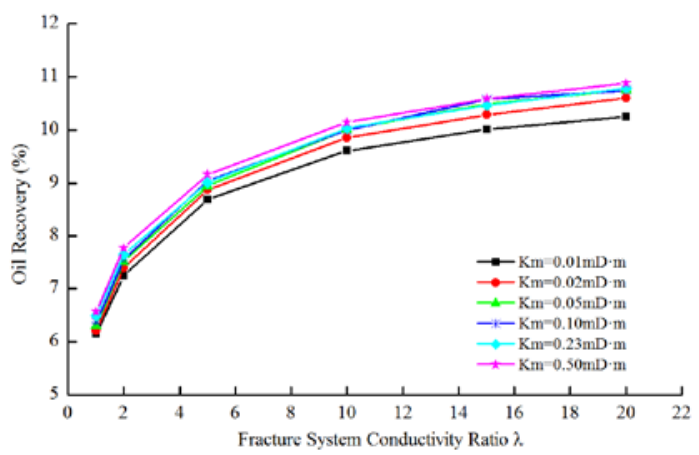

FIGURE VI. THE RELATIONSHIP BETWEEN FRACTURE SYSTEM CONDUCTIVITY RATIOS AND OIL RECOVERY UNDER DIFFERENT MATRIX PERMEABILITY

From fig.6 we can conclude that the matrix permeability has little influence on the optimized fracture system conductivity ratio. The relationship curve under different matrix permeability showed a uniform trend and all indicates a value of 10 as the optimized fracture system conductivity ratio, this is consistent with the previous results.

\section{CONCLUSIONS}

1) In a complex fracture system, increasing the fracture network conductivity provides little additional oil recovery of the fractured wells. This indicates that in network fracturing, the primary goal is to create a large size stimulated reservoir volume.

2) In a complex fracture system, the primary fracture conductivity affects the oil recovery a lot, increasing the conductivity will significantly increase the recovery, and there is a critical value(for the studied area is $200 \mathrm{mD} \cdot \mathrm{m}$ ) . This indicates that in network fracturing, some measures should be taken to enhance the conductivity of primary fracture, such as pumping larger proppants at the beginning of the fracturing treatment.

3) As the conductivity ratio of primary fracture and fracture network increase, the oil recovery increases. The value of 10 was determined as the optimized fracture system conductivity ratio with different fracture network conductivities.

4) The matrix permeability has little influence on the optimized fracture system conductivity ratio. The relationship curve under different matrix permeability showed a uniform trend and all indicates a value of 10 as the optimized fracture system conductivity ratio. This indicates that there is an 
opportunity to improve the recovery of tight oil reservoirs despite its low permeability.

\section{ACKNOWLEDGEMENTS}

The work and results reported here are part of Project 51404282 supported by National Natural Science Foundation of China and PetroChina Innovation Foundation(2014D-50060215).

\section{REFERENCES}

[1] Lin Senhu, Zou Caineng, Yuan Xuanjun, et al. Status of tight oil exploitation in the United States and its Implication. Lithologic Reservoirs, 23(4), pp. 25-30, 2011.

[2] Mayerhofer M, Lolon E, Warpinski N, et al. What is stimulated reservoir volume? SPE Shale Gas Production Conference, Fort Worth, Texas, U.S.A., pp.1-14, 2008.

[3] Mayerhofer M, Lolon E, Warpinski N, et al. What is stimulated reservoir volume? Production \& Operations, 25(1), pp. 89-98, 2010.

[4] Wu Qi, Xu Yun, Wang Tengfei, et al. The revolution of reservoir stimulation: an introduction of volume fracturing. Natural Gas Industry,31(4), pp. 36-39, 2011.

[5] Weng Dingwei, Lei Qun, Xu Yun, et al. Network fracturing techniques and its application in the field. ACTA PETROLEI SINICA, 32(2), pp. 280-284, 2011.

[6] Cipolla C L, Lolon E P, Erdle J C, et al. Modeling well performance in shale-gas reservoirs. SPE/EAGE Reservoir Characterization and Simulation Conference, Abu Dhabi, UAE, pp. 1-16, 2009.

[7] Cipolla, C.L., Warpinski, N.R., Mayerhofer, M.J., Lolon, E. P. The Effect of Proppant Distribution and Un-Propped Fracture Conductivity on Well Performance in Unconventional Gas Reservoirs. SPE Hydraulic Fracturing Technology Conference, Woodlands, Texas, USA, pp. 1-10, 2009.

[8] Cipolla C, Lolon E, Erdle J, et al. Reservoir modeling in shale-gas reservoirs. Reservoir Evaluation \& Engineering, 13(4), pp. 638-653, 2010.

[9] Cipolla, C.L. Modeling Production and Evaluating Fracture Performance in Unconventional Gas Reservoirs. International Petroleum Technology Conference, Beijing, China, pp. 1-10, 2013.

[10] Mayerhofer, M.J., Lolon, E.P., Youngblood, J.E., and Heinze, J.R. Integration of Microseismic Fracture Mapping Results with Numerical Fracture Network Production Modeling in the Barnett Shale. SPE Annual Technical Conference and Exhibition, San Antonio, Texas, U.S.A., pp. 1-8, 2006.

[11] Barry Rubin. Accurate Simulation of Non-Darcy Flow in Stimulated Fractured Shale Reservoirs. SPE Western Regional Meeting, Anaheim, California, USA, pp. 1-16, 2010. 